\title{
The known geographical distribution of sand flies in the state of Rondonia, Brazil (Diptera: Psychodidae) (1)
}

\author{
Ceclie B. Biancardi $\left({ }^{2}\right)$, Jorge R. Arias $\left({ }^{3}\right)$, Rui A. de Freitas $\left({ }^{3}\right)$, Eloy G. Castellon $\left({ }^{3}\right)$
}

\begin{abstract}
This study expands the knowledge of phlebotomine sand fly distribution in the state of Rondonia, Brazil. New state and country records are registered, bringing the total of known sand fly species in Rondonia to 78 .
\end{abstract}

\section{INTRODUCTION}

The only sand flies from the State of Rondonia previously reported were those by Martins et al. $(1965,1978)$. Martins et al. (1965) cited 40 species from Rondonia, two being in the genus Brumptomyia, thirty-seven in the genus Lutzomyia, and one in the genus Psychodopygus. Of the thirty-seven Lutzomyia, L. dubia became synonomous with $L$. odax, and $L$. abunaensis became synonomous with L. brasiliensis. Martins et al. (1978) added two more species in the genus Lutzomyia to this list, bringing the total number of previously described species to 42 .

In the present work we report a total of 62 species, 47 in the genus Lutzomyia and 15 in the genus Psychodopygus. Interestingly, Martins et al. $(1965,1978)$ reported 16 species which we did not collect, and we are now reporting 36 species which are newly recorded for Rondonia. The total number of species collected in Rondonia is now 78 (Table 1).

\section{MATERIALS AND METHODS}

During Leishmania studies in the State of Rondonia, we set out to make a survey of the total sand fly population, as recommended by Killick-Kendrick and Ward (1981). In order to do this we utilized four basic capture techniques: Manbait capture, tree base captures, Malaise trap captures and CDC miniature light trap captures. Sand flies were preserved in $70 \%$ ethyl alcohol, cleared in $\mathrm{KOH}$, and mounted in Berlese solution. Some specimens that were not mounted were examined in phenol.

\section{Results}

During our two year capture program we took a total of 15,418 sand flies, of which $26,4 \%$ were males and $73,6 \%$ were females (Table 2) .

Map 1. This detailed map of the State of Rondonia shows (in the form of numbers) the collecting areas from which sand flies are recorded, and this is shown on the respsctive distribution maps to follow. Area $1-$ the Guajará Mirim area from which Martins et al. (1965, 1978) record many species. Even though we collected from this area, the results will be published elsewhere, as they are part of a comparative work done with Dr. Martins. Area $2-$ a forest area, with much disturbance from man, approximately five kilomsters from the west bank of the Madeira River opposite Porto Velho. Area $3-$ the area that includes the first 40 kilometers east of Porto Velho along the BR-364 Highway. Area $4-$ was considered separately as it is part of an area which will eventually be flooded by the construction of a hydroelectric dam in the n-ar future. Area 5 - the city of Ariquemes. This is a forest area around the recently developed city of Ariquemes. Area $6-$ the city of $\mathrm{Ji}$ Paraná, formerly called Rondonia, an older, more established, community. Area $7-$ the city of Vilhena, a center of colonization projects, and an ecotome between terra firma forest and "cerrado".

\footnotetext{
(1) - This research was partly financed by a Grant in Aid from the Rondonia Territorial Government and CNPq's INPA project 3057.

(2) - Universidade Federal de Mato Grosso, Cuiabá.

(3) - Instituto Nacional de Pesquisas da Amazônia, Manaus.
} 


\section{Genus Brumptomyia (Map 2)}

The genus Brumptomyia is represented in the State of Rondonia by two species, $B$. pentacantha and $B$. pintoi, as reported by Martins et al. (1965) from the Guajará Mirim area. B. pentacantha is a broadly distributed species, ranging from Ecuador, Peru, Bolivia, and the Brazilian Amazen from Acre to Pará. B. pintoi has been found from French Guyana to Argentina. In Brazil, this last species has been found from Acre and Amazonas states south to São Paulo state. Our not recording further captures in this genus is probably due to differences in capture techniques used here as compared with those reported by Martins et al (1965) .

\section{Genus Lutzomyia \\ (Map 3)}

In the genus Lutzomyia, subgenus Lutzomyia, the series cruciata is represented by three species. L. gomezi, is the species with the

TABLE 1 - Sand fly species found in the state of Rondonia, Brazil

BRUMPTOMYIA França \& Parrot (1921)

Brumptomyia pentacantha (Barretto) (1947)

Brumptomyia pintoi (Costa Lima) (1932)

\section{LUTZOMYIA França (1924)}

Lutzomyia abonnenci (Floch \& Chassignet) (1947)

Lutzomyia anduzei (Rozeboom) (1942)

Lutzomyia antunesi (Coutinho) (1939)

Lutzomyia aragaoi (Costa Lima) (1932)

Lutzomyia auraensis (Mangabeira) (1942)

Lutzomyia bacula Martins, Falcão \& Silva (1965)

Lutzomyia "begonae" like

Lutzomyia brasiliensis (Costa Lima) (1932)

Lutzomyia calcarata Martins \& Silva (1964)

Lutzomyia caligata Martins, Falcão \& Silva (1965)

Lutzomyia campbelli (Damasceno, Causey \& Arouck) (1945)

Lutzomyia cerqueirai (Causey \& Damasceno) (1945)

Lutzomyia coutinhoi (Mangabeira) (1942)

Lutzomyia damascenoi (Mangabeira) (1941)

Lutzomyia dasymera (Fairchild \& Hertig) (1961)

Lutzomyia dasipodogeton (Castro) (1939)

Lutzomyia dendrophila (Mangabeira) (1942)

Lutzomyia dreisbachi (Causey \& Damasceno) (1945)

Lutzomyia evangelistai Martins \& Fraiha (1971)

Lutzomyia flabellata Martins \& Silva (1964)

Lutzomyia flaviscutellata (Mangabeira) (1942)

Lutzomyia flochi (Abonnenc \& Chassignet) (1948)

Lutzomyia furcata (Mangabeira) (1941)

Lutzomyia gomezi (Nitzulescu) (1930)

Lutzomyia infraspinosa (Mangabeira) (1941)

Lutzomyia inornata Martins, Falcão \& Silva (1965)

Lutzomyia longispina (Mangabeira) (1942)

Lutzomyia loretonensis (Llanos) (1965)

Lutzomyia lutziana (Costa Lima) (1932)

Lutzomyia marinkellei Young (1979)

Lutzomyia michopyga (Mangabeira) (1942)

Lutzomyia monstruosa (Floch \& Abonnenc) (1944)

Lutzomyia nevesi (Damasceno \& Arouck) (1956)

Lutzomyia nordestina (Mangabeira) (1942)

Lutzomyia "nordestina" like

Lutzomyia octavioi (Vargas) (1949)

Lutzomyia odax (Fairchild \& Hertig) (1961)
Lutzomyia pilosa (Damasceno \& Causey) (1944)

Lutzomyia richardwardi (Ready \& Fraiha (1981)

Lutzomyia rondoniensis Martins, Falcão \& Silva (1965)

Lutzomyia rorotaensis (Floch \& Abonnenc) (1944)

Lutzomyia runoides (Fairchild \& Hertig) (1953)

Lutzomyia saulensis (Floch \& Abonnenc) (1944)

Lutzomyia scaffi (Damasceno \& Arouck) (1956)

Lutzomyia sericea (Floch \& Abonnenc) (1944)

Lutzomyia serrana (Damasceno \& Arouck) (1949)

Lutzomyia servulolimai (Damasceno \& Causey) (1945)

Lutzomyia shannoni (Dyar) (1929)

Lutzomyia sherlocki Martins, Silva \& Falcão (1971)

Lutzomyia spinosa (Floch \& Abonnenc) (1942)

Lutzomyia termitophila Martins, Falcão \& Silva (1964)

Lutzomyia triacantha (Mangabeira) (1942)

Lutzomyia trinidadensis (Newstead) (1922)

Lutzomyia tuberculata (Mangabeira) (1941)

Lutzomyia ubiquitalis (Mangabeira) (1942)

Lutzomyia umbratilis Ward \& Fraiha (1977)

Lutzomyia walkeri (Newstead) (1914)

Lutzomyia whitmani (Antunes \& Coutinho) (1939)

Lutzomyia wilsoni (Damasceno \& Causey) (1945)

Lutzomyia yuilli Young \& Porter (1972)

Lutzomyia sp de Baduel (Floch \& Abonnenc) (1945)

PSYCHODOPYGUS Mangabeira (1941)

Psychodopygus amazonensis (Root) (1934)

Psychodopygus ayrozai (Barretto \& Coutinho) (1940)

Psychodopygus carrerai (Barretto) (1946)

Psychodopygus chagasi (Costa Lima) (1941)

Psychodopygus claustrei (Abonnenc, Leger \& Fauran) (1979)

Psychodopygus complexus (Mangabeira) (1941)

Psychodopygus corcssoniensis (LePont \& Pajot) (1978)

Psychodopygus davisi (Root) (1934)

Psychodopygus gujanensis (Floch \& Abonnenc) (1941)

Psychodopygus hirsutus (Mangabeira) (1942)

Psychodopygus lainsoni Fraiha \& Ward (1974)

Psychodopygus Ilanosmartinsi Fraiha \& Ward (1980)

Psychodopygus paraensis (Costa Lima) (1941).

Psychodopygus $\mathrm{sp} .1$

Psychodopygus sp. 2 


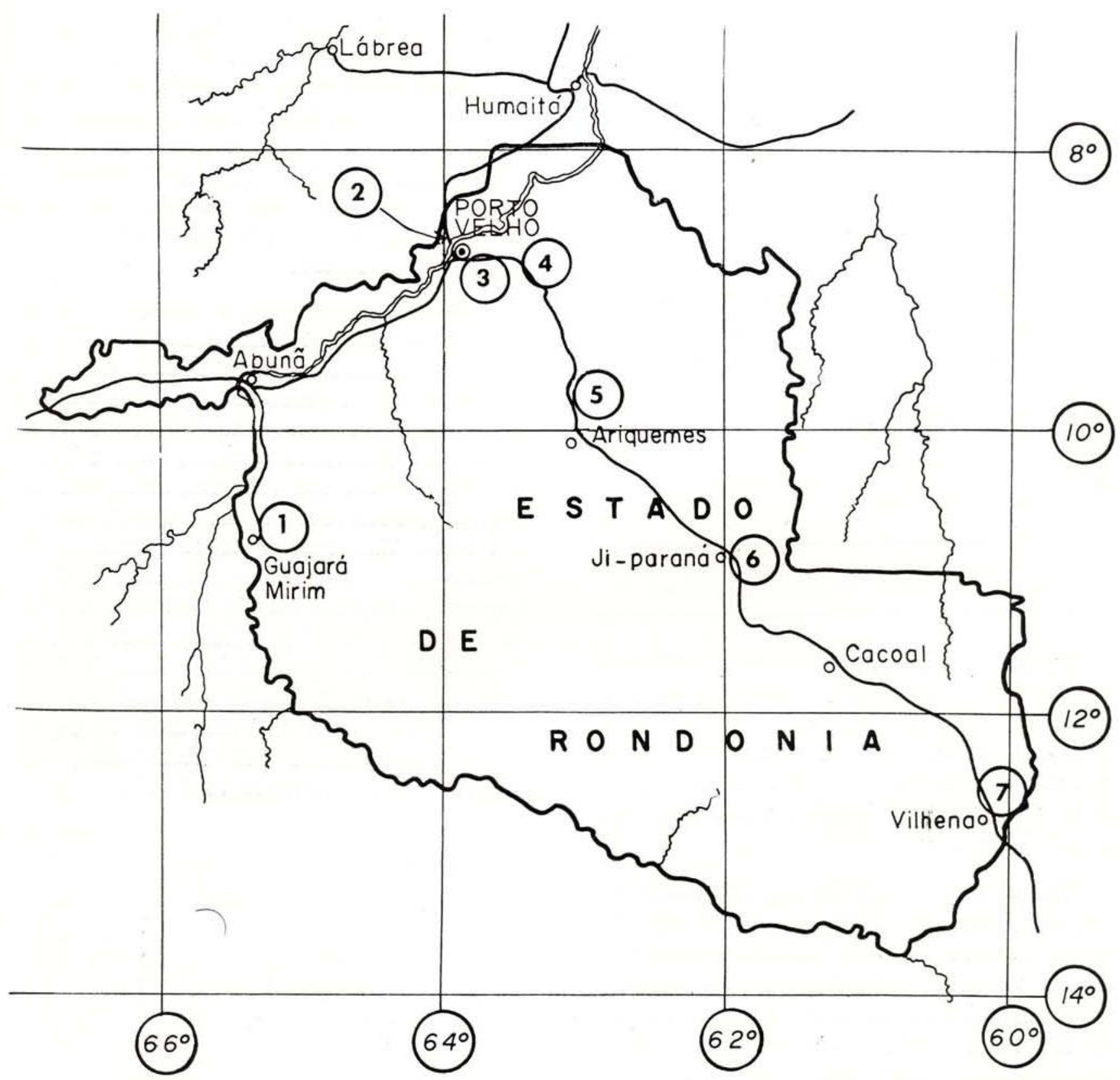

Map. 1 - Detailed map of the state of Rondonia showing the various geographical localitities and colletcting sites.

greatest distribution of this group, having been found from Guajará Mirim and Porto Velho to Vilhena. Even though this (and other species) was not taken in Ariquemes and Ji-Parana, it was probably due to the limited collections in those areas. Outside of Rondonia, this species has an extensive distribution, ranging from El Salvador in Central America through the Amazon Basin in Brazil to Maranhão and Mato Grosso states. L. sherlocki, previously only reported from Peru and Mato Grosso state in
Brazil, was taken from the $\mathrm{km} 48$ collection site to Ji-Parana. These collections were very limited in numbers. L. marinkellei WAS TAKEN ONLY ONCE, from the Vilhena collecting site. This species had only previously been reported from Colombia and Mato Grosso state in Brazil, this last collection site being close to Vilhena. Lutzomyia evangelistai is a species previously known from Peru and Para state, Brazil and was taken only from the Porto Velho and $\mathrm{Km} .48$ areas. 


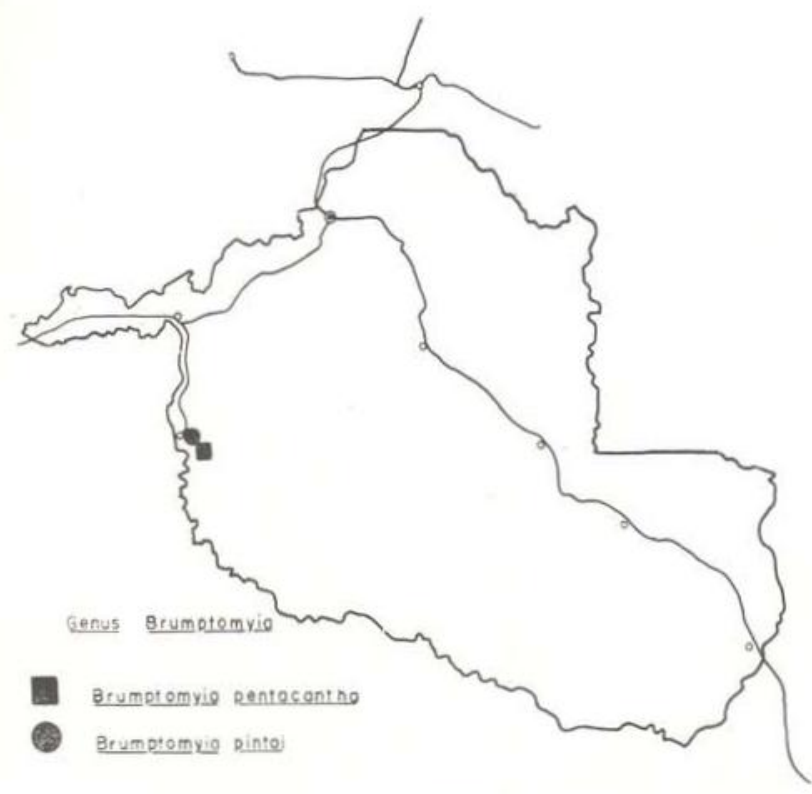

Map. 2 - Distribution of sand flies in the genus Brumptomyia from the state of Rondonia.

In the species group gasparviannai (Map $4)$, in the genus Lutzomyia, we only took L. flabellata. This species was collected from both ends of Rondonia, the Porto Velho area and the Vilhena area. Previous records place it only in the type locality, the neighboring state of Acre.

The walkeri series, in the species group migonei (Map, 5) of the genus Lutzomyia, is represented in the state by five species. $L$. bacula, which had previously been found in Rondonia and the state of Goias was taken only in the Porto Velho area. Previous authors (Martins et al., 1965, 1978; Young \& Fairchild, 1974) did not place this species in the walkeri series. We believe, based on morphological characters, such as in the tips of the ejaculatory ducts, that it belongs in this group. $L$. sericea, previously recorded from French Guyana and the northern part of the Brazilian Amazon was taken in small numbers in the Vilhena area. L. termitophila, previously recorded from Rondonia, Minas Gerais and Mato Grosso states, L. walkeri trom Peru, northern Brazil, Bolivia and Paraguay, and L. sp. of Baduel from" Colombia, French Guyana and Rondonia were not taken by us, but were reported by Martins et al. $(1965,1978)$.
Both of the species in the saulensis group (Map. 6) were taken. L. saulensis and L. wilsoni were taken at all collecting sites, except L. wilsoni was not found in the Ariquemes area. L. saulensis is a widely occurring species, being found from Costa Rica to throughout the Amazon Valley. L. wilsoni, on the other hand, is more restricted in distribution to Amazonas and Rondonia states.

The series verrucarum of the species group verrucarum (Map. 7), and the series serrana of the same species group, both in the genus Lutzomyia, are represented by three species, one in the first series, and two in the latter. $L$. nevesi (series verrucarum) was taken in the Porto Velho and Ji-Parana areas and had previously been recorded from the Guajara-Mirim area. This species is restricted to the eastern part of Peru and Bolivia, and the western part of the Brazilian Amazon. L. serrana (series serrana) previously recorded from Guajara-Mirim, was taken from Porto Velho to Ji-Parana. L. cdax (series serrana) has only been taken in the Porto Velho area. These last two species have a wide distribution, from northern Central America to Brazil.

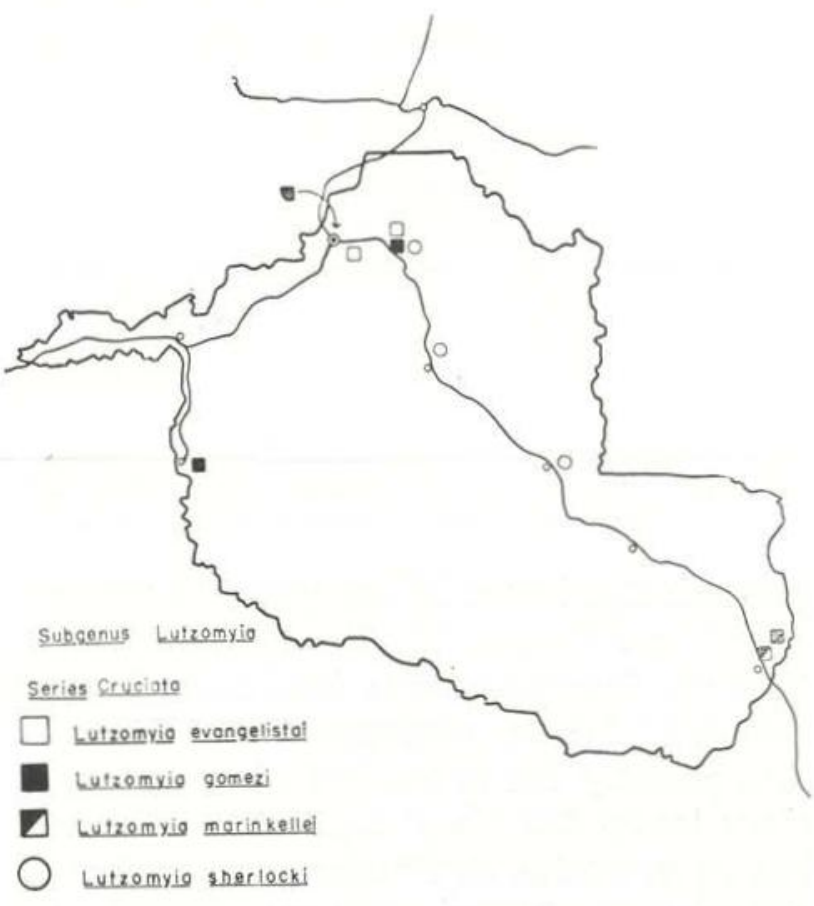

Map. 3 - Distribution of sand flies in the genus Lutzomyia, subgenus Lutzomyia, from the state of Rondonia. 
Two species of sand flies in the subgenus Pintomyia (Map. 8) are recorded from the Porio Velho and Vilhena extremes of Rondonia. L. spinosa, which has a broad distribution from Panama to the Brazilian Amazon, was taken more frequently than L. damascenoi, which has a known distribution from Colombia to the Brazilian Amazon.

Martins et al. (1978) recorded two species in the subgenus Pressatia (Map. 9) for the territory of Rundonia, both from the GuajaraMirim area. We took three females, which we believe to be $L$. triacantha, from the Porto VeIho and Ji-Parana areas. L. calcarata (the second species recorded by Martins et al.) is known from eastern Peru and Bolivia and the western Amazon of Brazil. L. triacantha has been recorded from central Colombia, eastern Peru, and the northern part of the Amazon Basin of Brazil.

Three species in the infraspinosa series and one in the monstruosa series of the subgenus Evandromya (Map 10) are recorded for Rondonia. Martins et al. $(1965,1978)$ record L. cerqueirai from Guajara-Mirim and L. infraspinosa from the Porto Velho area. We didn't collect either of these species during the study, but we did find both sexes of a sand fly which

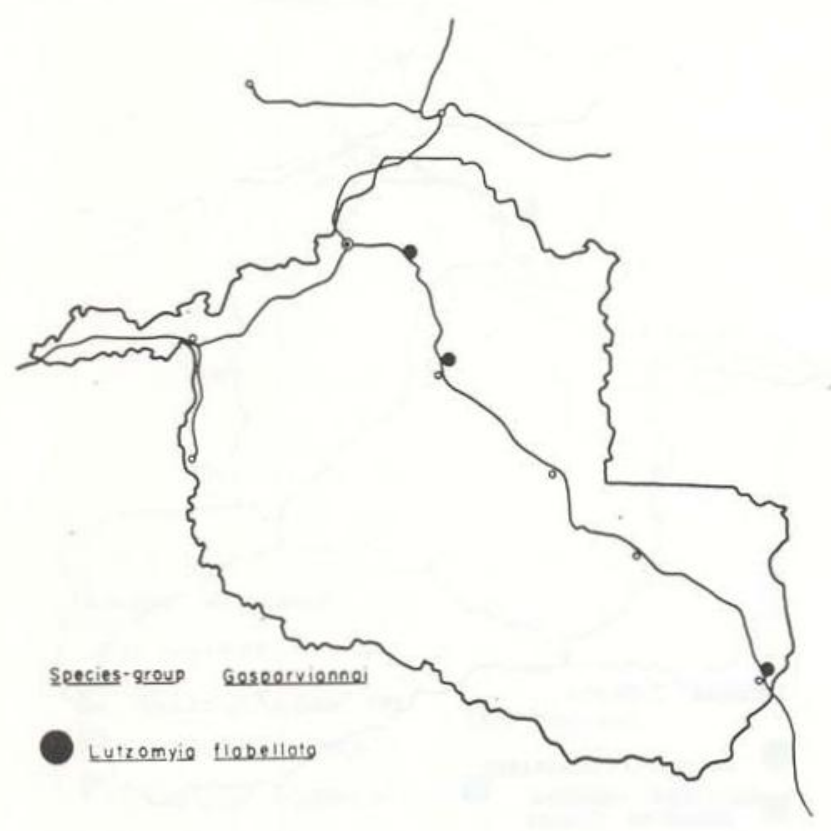

Map. 4 - Distribution of sand flies in the genus Lutzomyia, species-group gasparviannai, from the state of Rondonia.

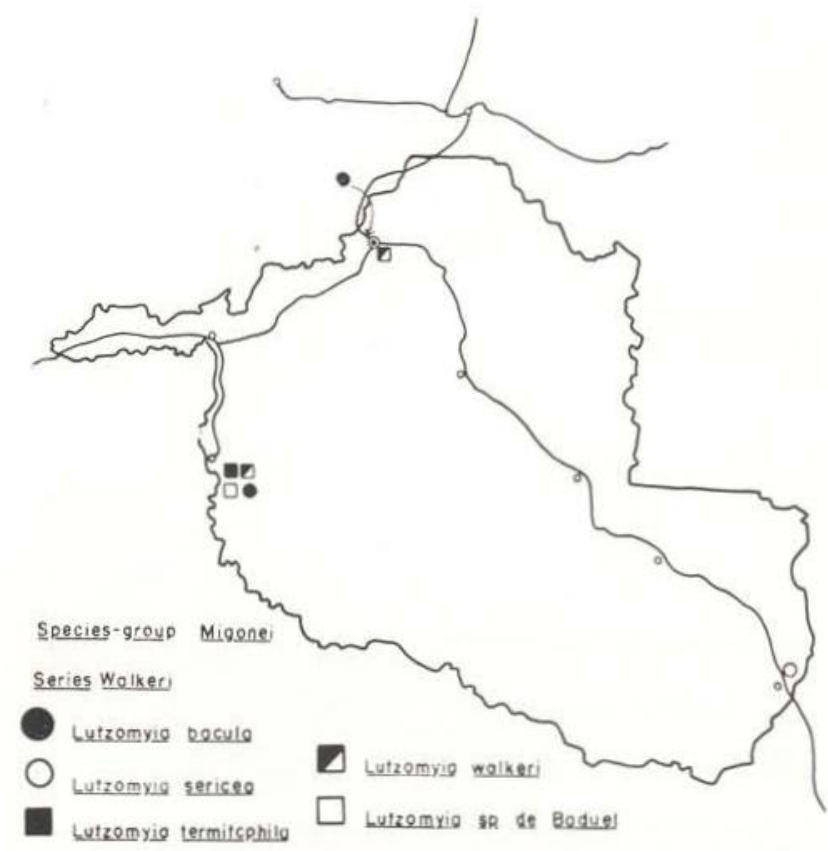

Map. 5 - Distribution of sand flies in the genus Lutzomyia, species-group migonei, from the state of Rondonia.

approximates $L$. infraspinosa and L. begonae. We have decicied to treat this species at a later date, and to avoid confusion with L. intraspinosa will call it $L$. "begonae-like". We have found this "begonae-like" sand fly all the way up to the Manaus area in the state of Amazonas, Brazil. L. cerqueirai is an Amazonian species, while $L$. infraspinosa has been recorded from French Guyana, Suriname, and the Brazilian Amazon. In the monstruosa series of this subgenus, L. monstruosa has been found in Porto Veiho and Guajara-Mirim in the state of Rondonia, its full known distribution being from French Guyana and most of the Brazilian Amazon Basin.

Both of the species in the subgenus Viannamyia (Map 11) which have been recorded for Rondonia, L. furcata and L. tuberculata, are widely distributed in the territวry. Their known geographical distribution rang-s from Central America to northern Brazil.

The shannoni group of sand flies (Map 12) is represented by seven species in Rondonia. L. dendrophila was the only species that was collected at all localities studied $L$. abbonenci, L. scaffi, and L. shannoni were present everywhere except Vilhena (where we had limited 


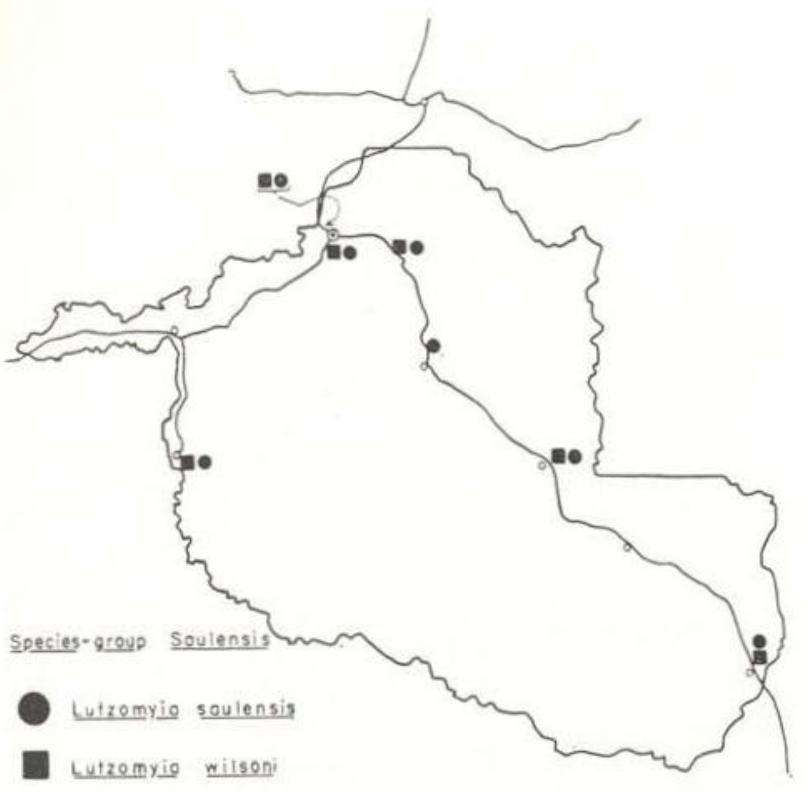

Map. 6 - Distribution of sand flies in the genus Lutzomyia, species-group saulensis, from the state of Rondonia.

collections). L. campbelli, $L$. dasymera and $L$. lutziana appear to be more restricted in their distribution in Rondonia, only having been taken in one or two collecting sites. Table 2 shows that there were over 1000 females in the "shannoni" group which were collected. These were not separated to species due to the difficulty of separating females of $L$. abonnenci, L. dendrophila, L. scaffi, and L. shannoni. The females of the other species in this group could be, and were separated. L. shannoni has one of the greatest ranges of distribution of New World species, having been recorded from the United States south to Argentina. $L$. abonnenci has a geographical distribution from Central America to Brazil; L. dasymera from Mexico to Colombia (this citation being a new country record); the other species in this group occur within the Amazon Basin of Brazil and some of the neighboring countries.

Longispina species group (Map 13) females are also indistinguishable and we have grouped all 247 specimens collected into one group. The species in this group which are represented in Rondonia (as seen from the males) are $L$. rondonfensis and $L$. dasipodogeton, which are distributed throughout the state, and $L$. Iongispina, which was only taken on the west bank of the Madeira River near Porto Velho. The known distribution of $L$. dasipodogeton and L. rondoniensis is restricted to Rondonia, while L. longispina had been taken from Colombia, Venezuela and much of Brazil.

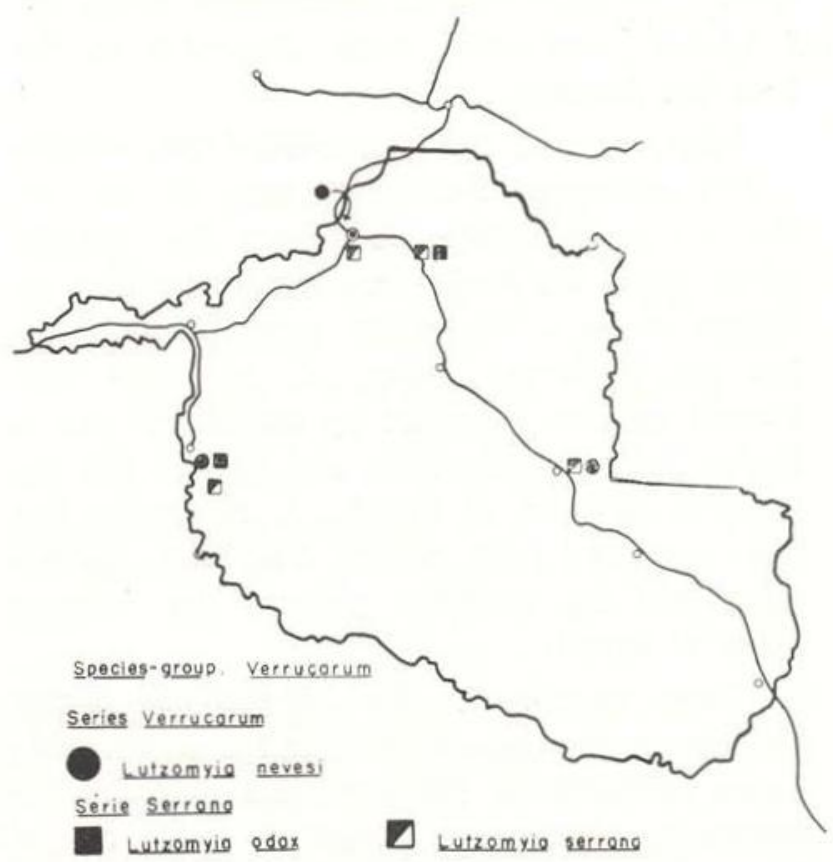

Map. 7 - Distribution of sand flies in the genus Lutzomyia, species-group verrucarum, from the state of Rondonia.

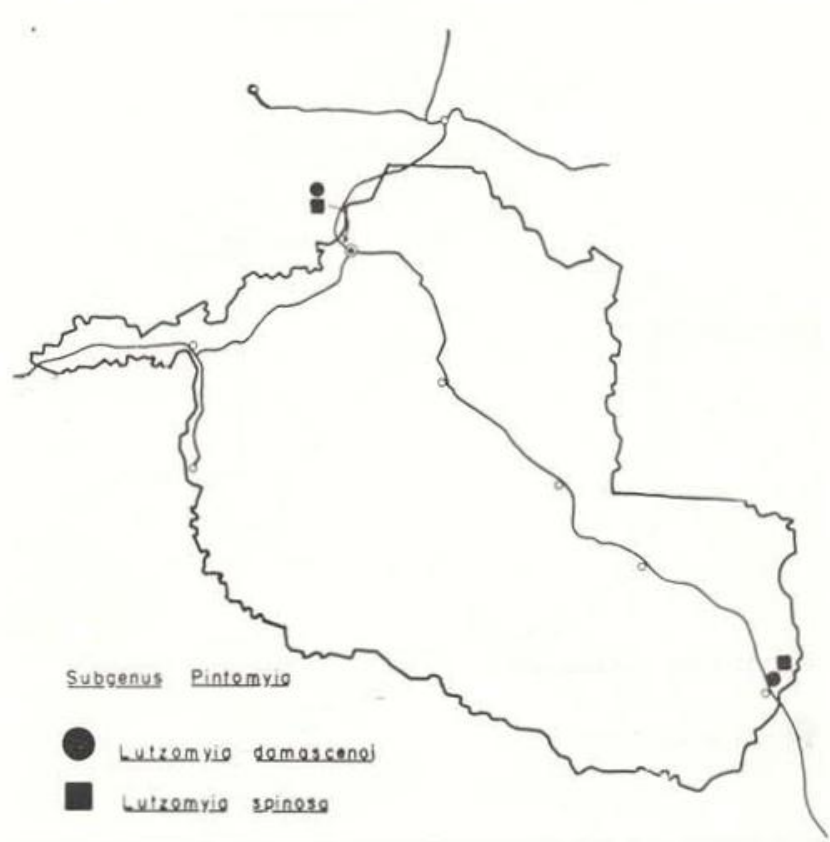

Map. 8-Distribution of sand flies in the genus Lutzomyia, subgenus Pintomyia, from the state of Rondonia. 
Four species are recorded for Rondonia from the aragaoi species group (Map 14). L. aragaoi and $L$. coutinhoi in the aragaoi series and $L$. brasiliensis and $L$. runoides in the brasiliensis series. L. aragaoi is widely distributed

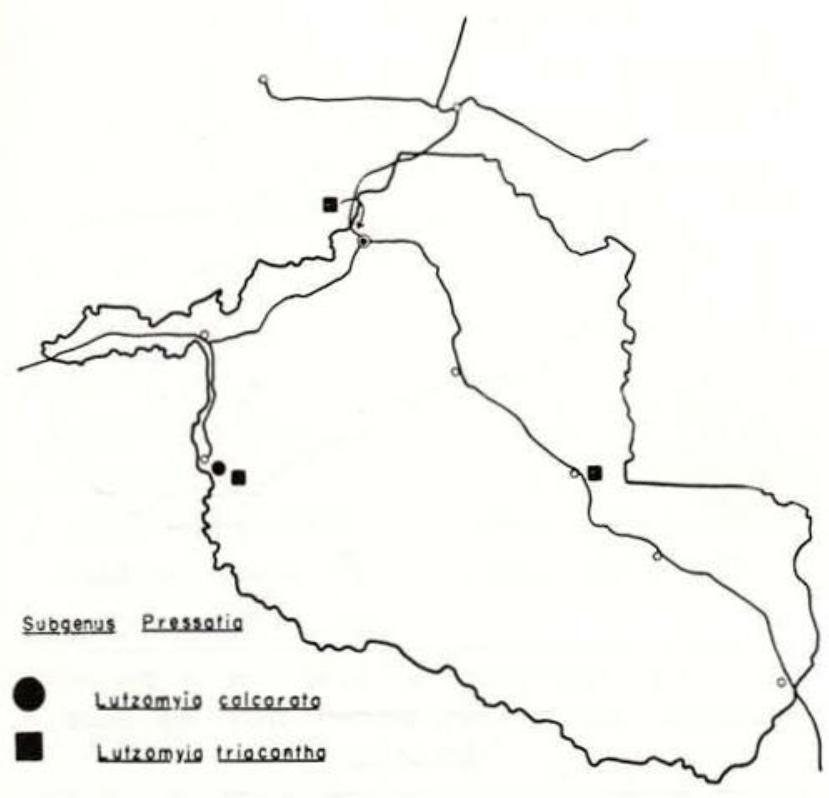

Map. 9 - Distribution of sand flies in the genus Lutzomyia, subgenus Pressatia, from the state of Rondonia.

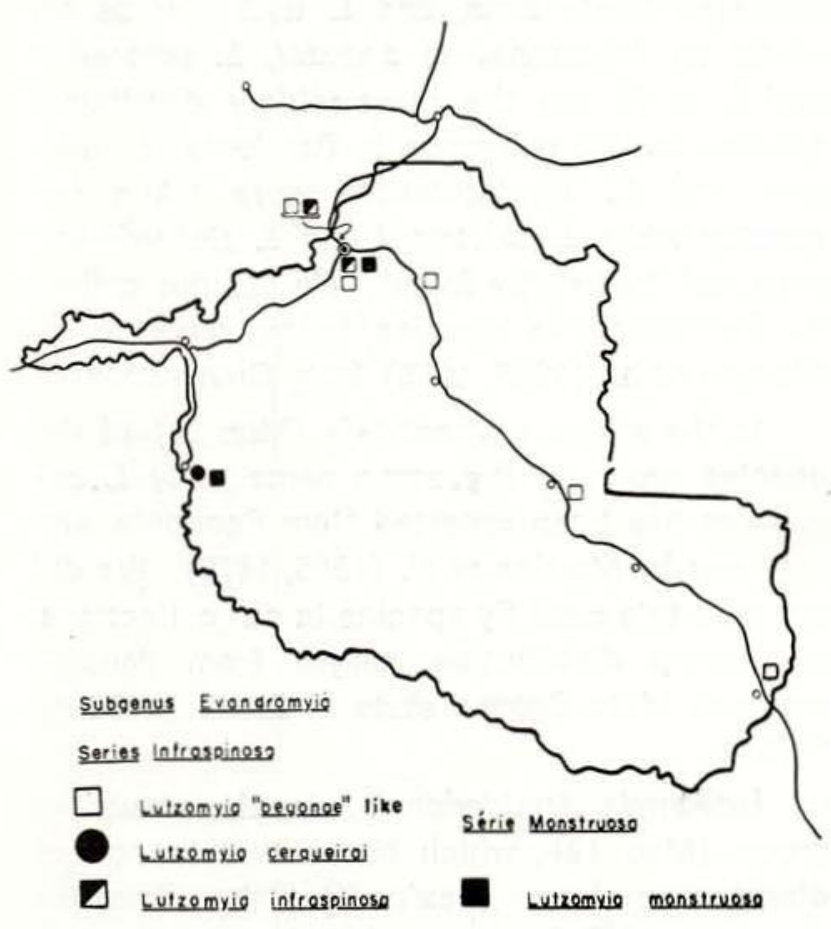

Map. $\$ 10$ - Distribution of sand flies in the genus Lutzomyia, subgenus Evandromyia, from the state of Rondonia.

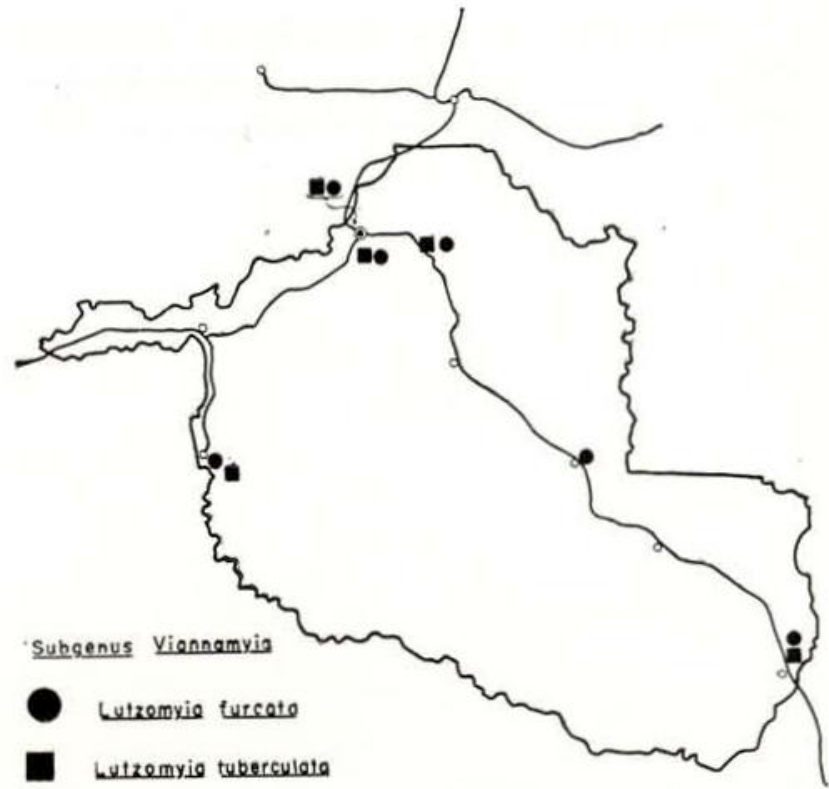

Map. 11 - Distribution of sand flies in the genus Lutzomyia, subgenus Viannamyia, from the state of Rondonia.

throughout the state, while the other species have only been taken from the Guajara-Mirim and Porto Velho areas. L. aragaoi ranges from Panama to Paraguay; L. runoides from Costa Rica to Brazil and the other two species are more restricted in their distribution to the northern Amazon Basiri of Brazil, even though $L$. brasiliensis can also be found throughout southern Brazil.

Only L. direisbachi of the dreisbachi species group (Map 15) was taken in two collecting sites near the Porto Velho area. This is an Amazonian species, known from Colombia, Brazil and French Guyana.

Sand flies in the subgenus Trichophoromyia (Map 16) were represented by five species in Rondonia. Martins et al. (1978) recorded all of these, except for L. loretonensis, from GuajaraMirim and only $L$. auraensis from Guajara-Mirim and Porto Velho. We found L. octavioi and L. ubiquitalis to be present throughout Rondonia, whıle L. loretonensis and L. flochi were taken in the northern part of the State. Previously, L. loretonensis had only been recorded from Peru, thus establishing here a country record for Brazil. The other species of Trichophoromyia recorded here have a broad distribution in northern South America. 
Sand flies in the subgenus Nyssomyia (Map 17) were represented by eight species. Most of these species are Amazonian in distri-

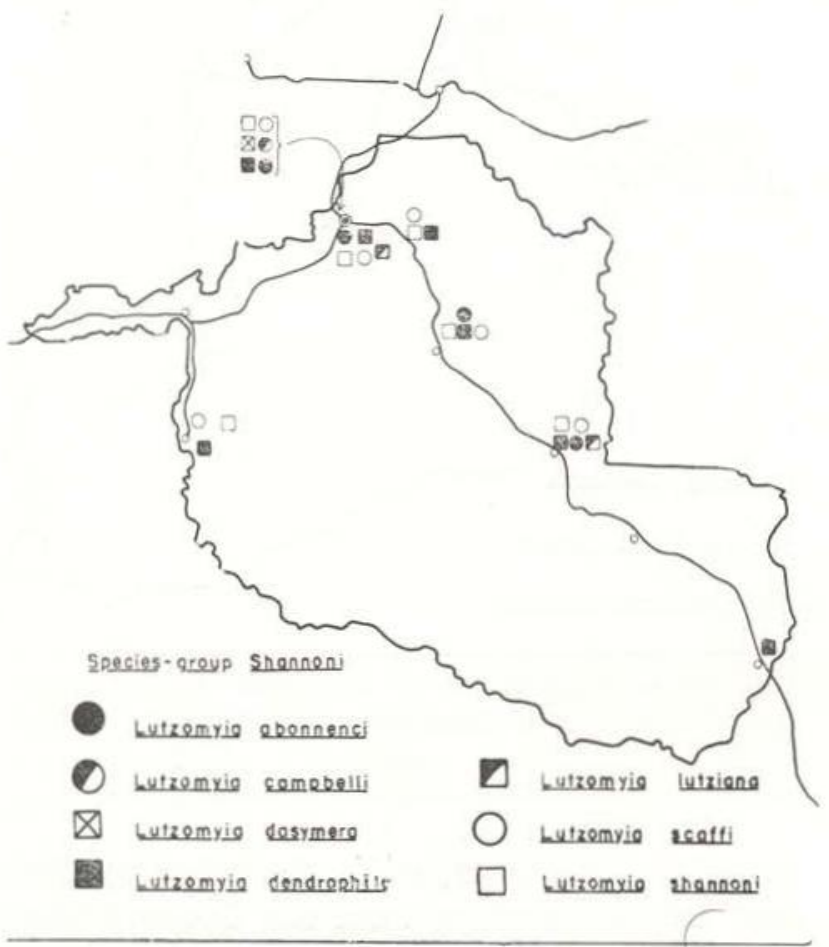

Map. 12 - Distribution of sand flies in the genus Lutzomyia, species-group shannoni, from the state of Rondonia.

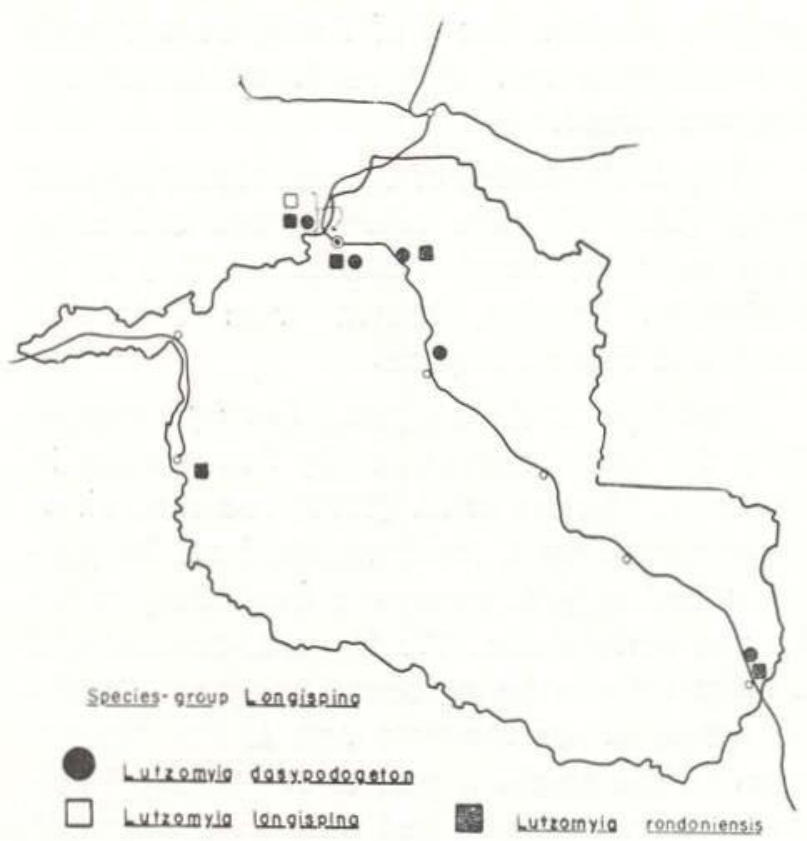

Map. 13 - Distribution of sand flies in the genus Lutzomyia, species-group longispina, from the state of Rondonia.

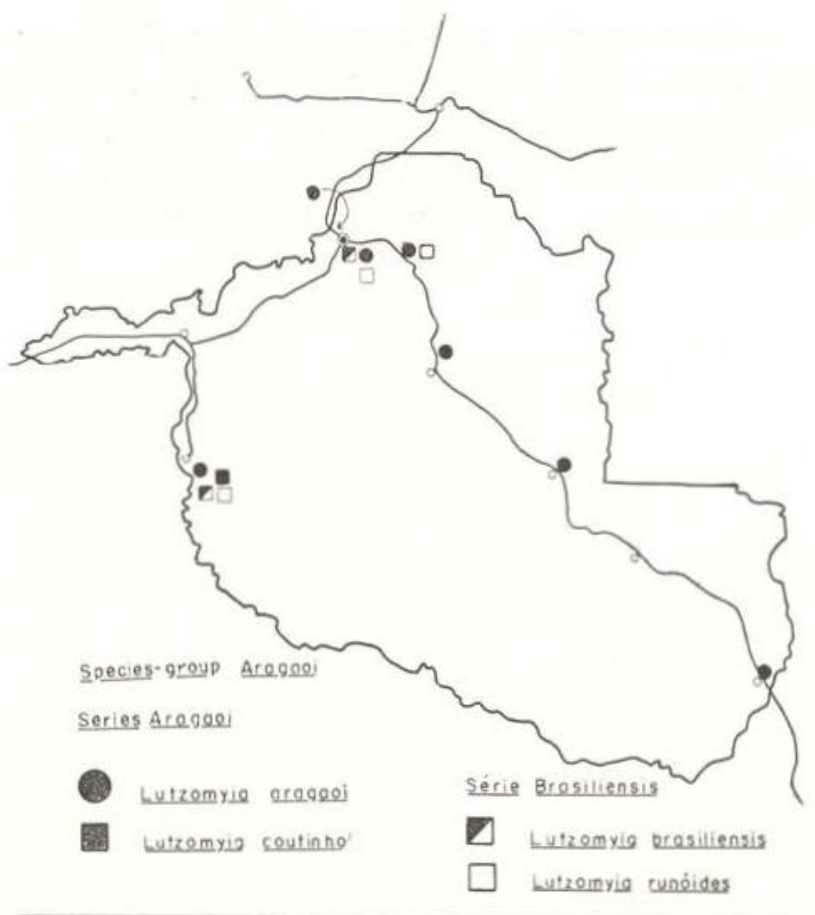

Map. 14 - Distribution of sand flies in the genus Lutzomyia, species-group aragaoi, from the state of Rondonia.

bution, and some extend into southern Brazil and neighboring countries, L. anduzei as far north as Costa Rica, and L. whitmani as far south as Argentina. L. anduzei, L. umbratilis and $L$. yuilli are the most widely distributed species in this subgenus in Rondonia. L. antlinesi and $L$. flaviscutellata were taken frequently while $L$. whitmani and $L$. richardwardi were not frequently found. We did not collect $L$. inornata; this species being reported by Martins et al. $(1965,1978)$ from Guajara-Mirim.

In the series cavennensis (Map 18) of the species group of the same name, only $L$. micropyga has been reported from Rondonia, and that was by Martins et al. $(1965,1978)$. We did not take this sand fly species in our callections. Its known distribution ranges from Panama south to Mato Grosso state in Brazil, and into Bolivia.

Lutzomyia trinidadensis, in the oswaldoi group (Map 19), which has a wide range of distribution from Mexico to the Brezilian Amazon and Bolivia, was found to be present in all our collection sites, except the area on the western bank of the Madeira River, across from Porto Veiho. L. rorotaensis, in this same 
group, was taken in limited numbers from the Ariquemes area. This species has previously been recorded from Colombia, French Guiana and northernmost Brazil.

Lutzomyia pilosa (Map 20), the only species collected from the pilosa group was only taken at eight locations around the Porto Velho area, on both sides of the river. This sand fly is widely distributed from Costa Rica south through Colombia to the northern part of the Brazilian Amazon.

Four species of sand flies, which have not yet been placed in any group, have been taken in Rondonia (Map 21) . L. caligata (which Martins et al. (1978) placed in the amarali group), L. nordestina, and L. servulolimai were recorded by Martins et al. (1965, 1978), and we found one other species which appears near $L$. nordestina, yet may not be this species. This L. sp. (near nordestina) was taken from Porto Velho to Vilhena. We did not take the other species referred to on this map. L. caligata is found only from Guajara-Mirim; L. nordestina being reported from Panama to southern Brazil, and L. servulolimai is known from Peru eastward to Para state in Brazil.

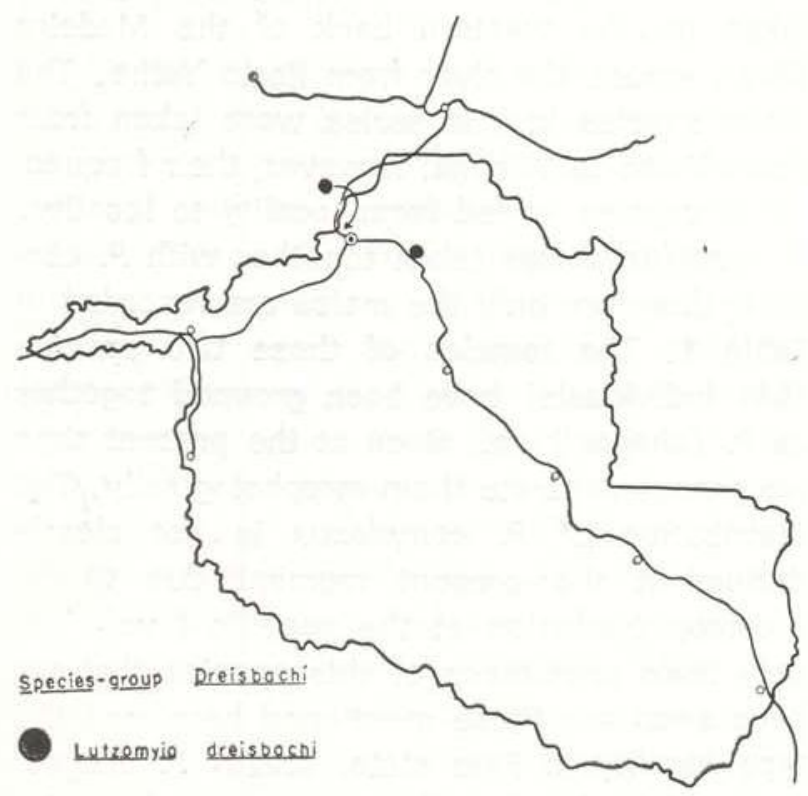

Map. 15 - Distribution of sand flies in the genus Lutzomyia, species-group dreisbachi, from the state of Rondonia.

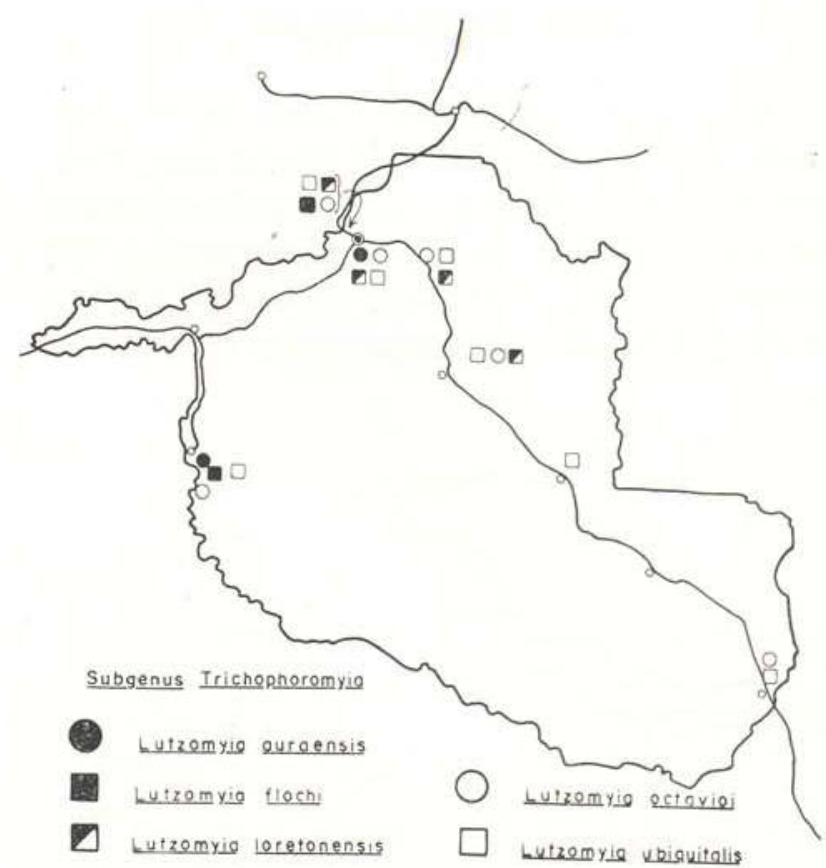

Map. 16 - Distribution of sand flies in the genus Lutzomyia, subgenus Trichophoromyia, from the state of Rondonia.

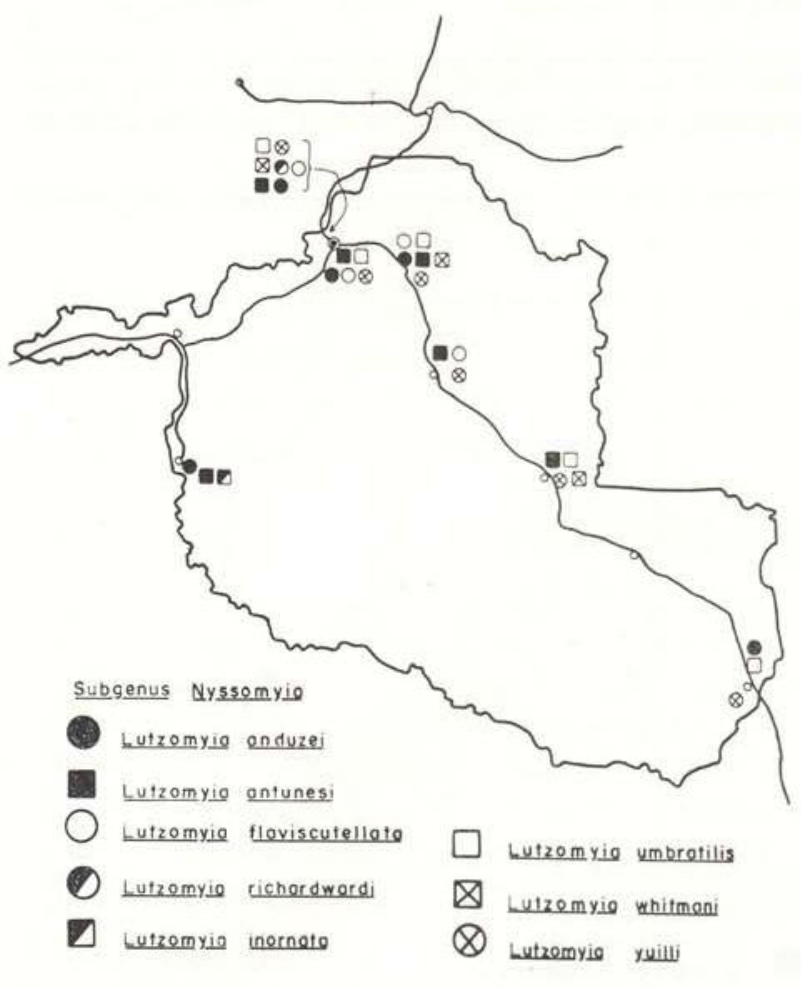

Map. 17 - Distribution of sand flies in the genus Lutzomyia, subgenus Nyssomyia, from the state of Rondonia.

The known. 


\section{Genus Psychodopygus}

At present there exists some controversy in the generic status of New World sand flies, and many authors do not consider Psychodopygus a valid genus, but rather a subgenus in the genus Lutzomyia. We have chosen, based on existing evidence and arguments, to consider

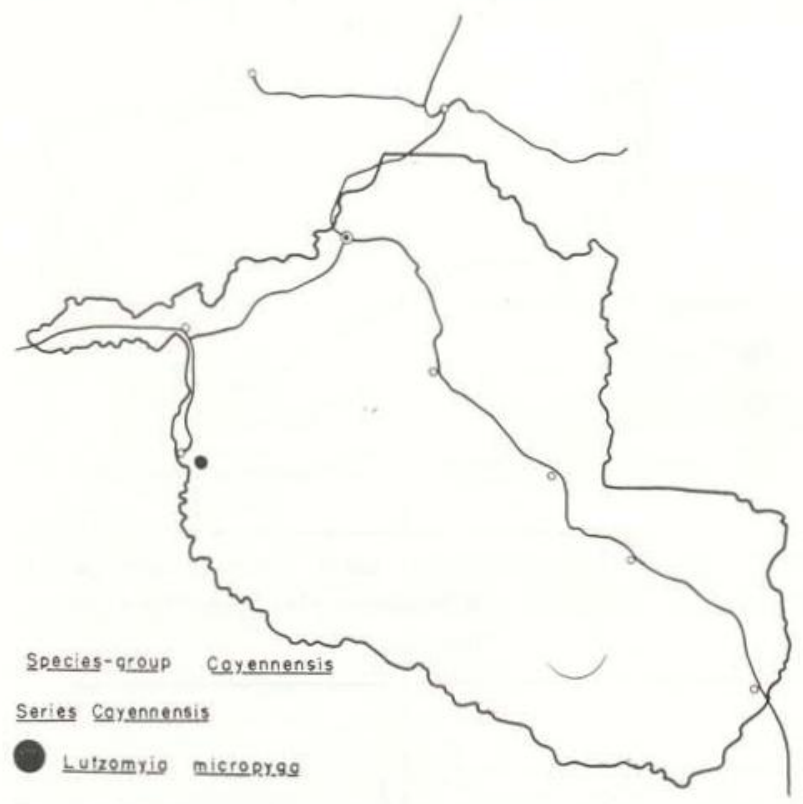

Map. 18 - Distribution of sand flies in the genus Lutzomyia, species-group cayennensis, from the state of Rondonia.

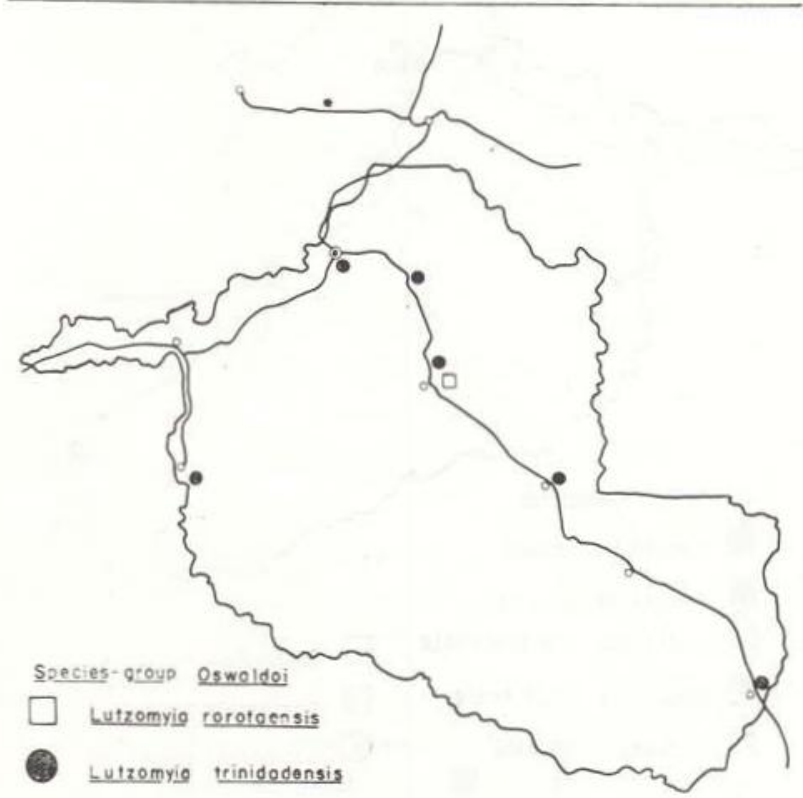

Map. 19 - Distribution of sand flies in the genus Lutzomyia, species-group oswaldoi, from the state of Rondonia.

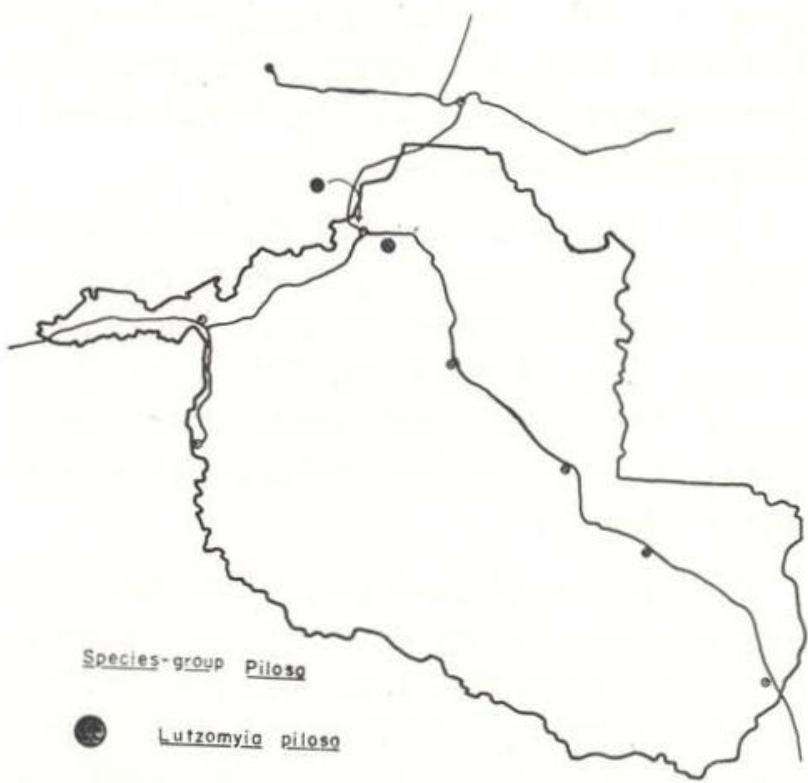

Map. 20 - Distribution of sand flies in the genus Lutzomyia, species-group pilosa, from the state of Rondonia.

this as a valid genus until general agreement is reached by specialists, as to level of recognition.

We took five species of the chagasi series in the genus Psychodopygus (Map. 22). P. Iainsoni was the only species in this series that was not widely distributed, only having been taken on the western bank of the Madeira River, across the river from Porto Velho. The other species in this series were taken from Porto Velho to Vilhena; however, their frequency of capture varied from locality to locality. $P$. complexus was taken together with $P$. chagasi; therefore only the males are recorded in Table 1. The females of these two sp:cies (641 individuals) have been grouped together as $P$. (chagasi) sp., since at the present time we cannot separate them morphologically. The distribution of $P$. complexus is not clearly defined at the present moment due to the previous confusion at the specific level. The only male specimens of this species that we have seen are those mentioned here. and the type locality is Para state, Brazil. P. chagasi is a widely distributed species throughout the Amazon Basin in Colombia, Peru and Brazil. $P$. corossoniensis, another of the species taken in this series, is closely related to $P$. guyanen- 


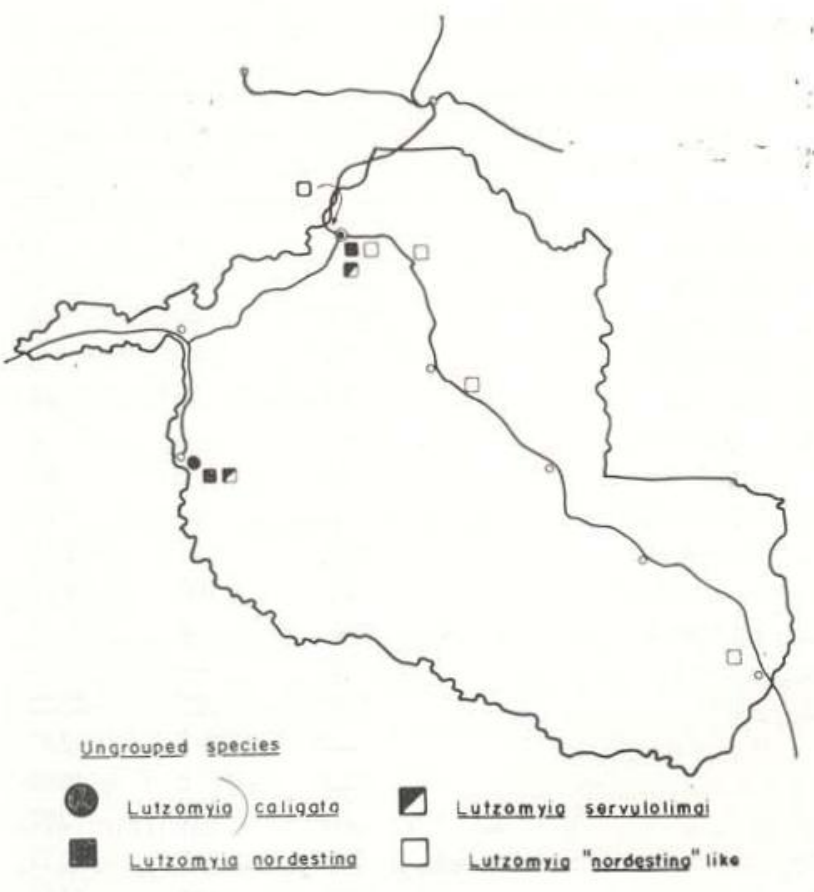

Map. 21 - Distribution of ungrouped sand flies in the genus Lutzomyia from the state of Rondonia.

sis, and was only known from the male from French Guyana. P. guyanensis has been reported from Belize (British Honduras) to the Amazon Basin of Brazil. P. lainsoni had only previously bee: reported from the type locality in Para state, Brazil.

The series panamensis (Map. 23) in the genus Psychodopygus is represented in Rondonia by ten species, two of which we feel are new, yet will treat separately because they require more study. These have been referred io on the maps as $P$. sp. № 1 , which is closely related to $P$. davisi; and $P$. sp. No 2, which is closely related to $P$. carrerai. Both of these species were found from Porto Velho to $\mathrm{Ji}$ Parana. P. amazonensis (as recently defined by Fraiha et al., 1980) was taken in all localities, except Vilhena. The known distribution of this species is that of the Amazon Basin. P. ayrozal (as defined by Young, 1980) and which has a range from Panama to southern Brazil, is widely distributed throughout the state. P. carrerai, P. davisi, P. paraensis, and $P$. hirsutus were taken throughout the territory and most of these have the same general distribution throughout the Amazon Basin, yet

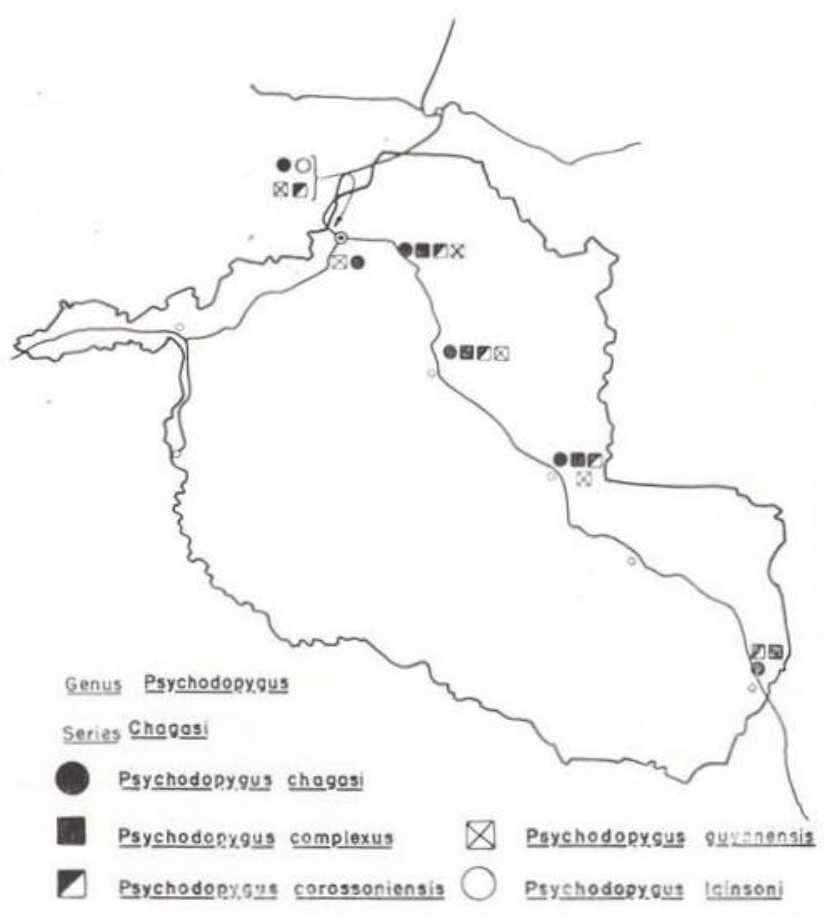

Map. 22 - Distribution of sand flies in the genus Psychodopygus, series elvagasi, from the state of Rondonia.

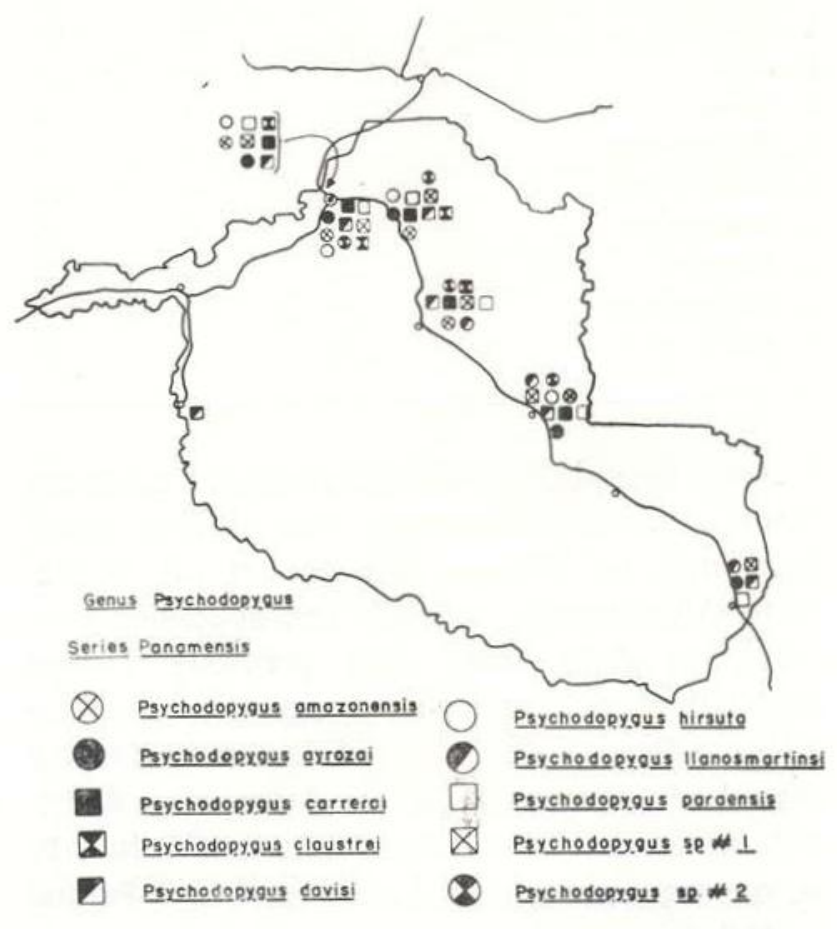

Map. 23 - Distribution of sand flies in the genus Psychodopygus, series panamensis, from the state of Rondonia.

The known... 
TABLE 2 - Sand Flies captured in Rondonia, Brazil, s?parated by sex

\begin{tabular}{|c|c|c|c|}
\hline Species & males & females & total \\
\hline Lutzomyia abonnenci & 33 & 一 & 33 \\
\hline L. anduzei & 44 & 267 & 311 \\
\hline L. antunesi & 1079 & 1529 & 2608 \\
\hline L. aragaoi & 42 & 50 & 92 \\
\hline L. bacula & 1 & - & 1 \\
\hline L. "begonae" like & 4 & 66 & 70 \\
\hline L. campbelli & 1 & - & 1 \\
\hline L. damascenoi & 3 & - & 3 \\
\hline L. dasymera & - & 1 & 1 \\
\hline L. dasypodogeton & 109 & 一 & 109 \\
\hline L. dendrophila & 538 & - & 538 \\
\hline L. dreisbachi & 2 & - & 2 \\
\hline L. evangelistai & 2 & - & 2 \\
\hline L. flabellata & 15 & - & 15 \\
\hline L. flaviscutellata & 32 & 82 & 114 \\
\hline L. flochi & 2 & - & 2 \\
\hline L. furcata & 15 & 28 & 43 \\
\hline L. gomezi & - & 4 & 4 \\
\hline L. longispina & 7 & - & 7 \\
\hline L. loretonensis & 85 & - & 85 \\
\hline L. lutziana & - & 1 & 1 \\
\hline L. marinkellei & 1 & - & 1 \\
\hline L. monstruosa & - & 3 & 3 \\
\hline L. nevesi & - & 8 & 8 \\
\hline L. "nordestina" like & 3 & 10 & 13 \\
\hline L. octavioi & 41 & - & 41 \\
\hline L. odax & 1 & - & 1 \\
\hline L. pilosa & 1 & 7 & 8 \\
\hline L. richardwardi & - & 1 & 1 \\
\hline L. rondoniensis & 62 & 一。 & 62 \\
\hline L. rorotaensis & 8 & 8 & 16 \\
\hline L. runoides & 23 & 8 & 31 \\
\hline L. saulensis & 5 & 33 & 38 \\
\hline L. scaffi & 85 & - & 34 \\
\hline
\end{tabular}

P. davisi can also be found throughout southern Brazi!. P. llanosmartinsi was found more frequently in Vilhena and not at all in the Porto Velho region, and only one specimen was taken in Ariquemes. The previous known distribution of this species was the type locality in Peru; thus, this also is a new country record. P. claustrei, also of Amazonian distribution, was taken from Porto Velho to Ariquemes, not having been found in Ji-Parana or Vilhena.

Recently Aboninenc et al. (1980) described $P$. robini, yet from Fraiha et al. (1980) papers, Young (personal communication), and our

\begin{tabular}{|c|c|c|c|}
\hline Species & males & females & total \\
\hline L. sericea & 4 & - & 4 \\
\hline L. serrana & - & 8 & 8 \\
\hline L. shannoni & 244 & - & 244 \\
\hline L. sherlocki & 4 & - & 4 \\
\hline L. spinosa & 18 & 8 & 26 \\
\hline L. triacantha & - & 3 & 3 \\
\hline L. trinidadensis & 33 & 7 & 40 \\
\hline L. tuberculata & 4 & 68 & 72 \\
\hline L. ubiquitalis & 129 & 131 & 260 \\
\hline L. umbratilis & 55 & 366 & 421 \\
\hline L. whitmani & - & 4 & 4 \\
\hline L. wilsoni & 15 & - & 15 \\
\hline L. yuilli & 107 & 1925 & 2332 \\
\hline L. (Longispina) sp. & - & 247 & 247 \\
\hline L. (Shannoni) sp. & - & 1079 & 1079 \\
\hline L. (Trichophoromyia) sp. & - & 387 & 387 \\
\hline Psychodopygus amazonensis & 9 & 18 & 27 \\
\hline P. ayrozai & 260 & 1181 & 1441 \\
\hline P. carrerai & 28 & 671 & 699 \\
\hline P. chagasi & 114 & - & 114 \\
\hline P. claustrei & 28 & 90 & 118 \\
\hline P. complexus & 9 & - & 9 \\
\hline P. corossoniensis & 15 & 184 & 199 \\
\hline P. davisi & 312 & 1233 & 1545 \\
\hline P. guyanensis & 14 & 112 & 126 \\
\hline P. hirsutus & 20 & 205 & 225 \\
\hline P. lainsoni & 2 & 5 & 7 \\
\hline P. Ilanosmartinsi & 4 & 64 & 68 \\
\hline P. paraensis & 7 & 432 & 439 \\
\hline P. sp. 1 & 88 & 90 & 178 \\
\hline P. sp. 2 & 15 & 72 & 87 \\
\hline P. (Chagasi) sp. & - & 641 & 641 \\
\hline Total & 4081 & 11337 & 15418 \\
\hline
\end{tabular}

independent observations, we have concluded that this species is synonomous with $P$. amazonensis.

\section{Discussion}

Martins et al. $(1965,1978)$ cite 42 species from Rondonia, of which we collected only 26 species. We collected 36 further species which were not previously reported from Rondonia, bringing the total known sand fly fauna of the state to 78 species.

Previous authors reported only Psychodopygus davisi in this genus, while we report 15 species for this genus. This great difference 
is undoubtedly due to the collecting methods. Sand flies in the genus Psychodopygus are rarely taken on natural resting sites or animal burrows, which was the principal methodology they used. Our study, in addition to utilizing tree base captures, also utilized CDC miniature light traps, and man-biting captures ( $\left.{ }^{*}\right)$. These last two capturing techniques yield many sand flies in this genus.

\section{AckNowledgments}

We would like to thank Mr. Artemio CoeIho da Silva for the artistic help, and Mr. João Ferreira Vidal, Mr. Raimundo Nonato Lima Santos for their field help, and Secretaría de Administração of the old Federal Territory of Rondonia for their support, and SUCAM teams for their logistical help.

\section{RESUMO}

Este trabalho expande o conhecimento da distribuição geográfica da fauna flebotômica do Estado de Rondônia, Brasil. Ncvos registros de espécies para o Estado e o País são apresentados, levantando o total de 78 espécies conhecidas em Rondônia.

\section{REFERENCES}

ABONNENC, E.; ARIAS, J.R.; LEGER, N.; YOUNG, D.G. 1980 - Sur Lutzomyia davisi (Root, 1934) et les es. pèces de morphologie comparable (Diptera Phlebotomidae). Ann. Parasit. (Paris), 55 (6): 707-719.

FRAIHA, H.; WARD, R.D.; QUINTANA, J.

1980 - Taxonomia de Psychodopygus amazonensis (Root, 1934) (Diptera, Psychodidae, Phlebotominae). Revta da FSESP, 25 (1): 5-9.

KILLICK-KENDRICK, R. \& WARD, R.D.

1981 - Workshop n. 11. Ecology of Leishmania. Parasitology, 82: 143-152.

MARTINS, A.V.; FALCÃO, A.L.; SILVA, J.E.

1965 - Notas sobre os flebótomos do Território de Rondônia. com a descrição de seis espécies novas (Diptera, Psychodidae). Revta bras. Biol., 25: 1-20.

MARTINS, A.V.; WILLIAMS, P.; FALCÃO, A.L.

1978 - American Sand Flies (Diptera: Psychodidae, Phlebotominae). Academia Brasileira de Ciências. Rio de Janeiro, Brazil. 194pp.

YOUNG, D.G.

1980 - A Review of the Bloodsucking Psychodid Flies of Colombia (Diptera: Phlebotominae and Sycoracinae). Ag. Exper. Sta. U. of Florida, Gainesville, U.S.A. 266pp.

YOUNG, D.G. \& FAIRCHILD, G.B.

1974 - Studies of Phlebotomine Sand Flies. Annual Report, U.S. Army Research and Development Command, Washington, D.C., U.S.A.

(Aceito para publicação em $08 / 02 / 82$ )

\footnotetext{
$(\bullet)$ - Even though we utilized man-biting captures in this study, we no longer use this method of capturing sand-flies due to the high risk involved.
} 